\title{
Alfabetización, gráficos y aprendizaje heurístico
}

\section{Eloy Martos-Núñez}

Universidad de Extremadura, España emartos@unex.es

\section{Aitana Martos-García}

Universidad de Almería, España aitmartos@gmail.com

\section{Resumen}

Se describen ciertos tipos de gráficos como herramientas de investigación cualitativa utilizadas en la formación de profesores de la Facultad de Educación de la Universidad de Extremadura, a partir de un Proyecto de Innovación Docente. Se parte de la hipótesis de que los alumnos universitarios no son lectores formados ni expertos, sino lectores en construcción, que adolecen de los mismos problemas de los lectores precarios o superficiales y que, por tanto, deben diagnosticar y corregir su propia situación como mejor ejemplo y entrenamiento de cara a su intervención en contextos de aula. Se ponen en valor sus cualidades heuristicas y de autorreflexión de cara a las competencias profesionales del docente.

\section{Palabras clave}

Pedagogía universitaria; formación de profesores; enseñanza de la lectura y la escritura; investigación de aula; Universidad de Extremadura, España (Fuente: Tesauro de la Unesco).

Recepción: 2015-01-15 | Envío a pares: 2015-02-21 | Aceptación por pares: 2015-09-21 | Aprobación: 2015-10-05 


\title{
Literacy Teaching, Graphics and Heuristic Learning
}

\begin{abstract}
Certain types of graphics are described as qualitative research tools used in teacher education at the Universidad de Extremadura School of Education, as part of its Teaching Innovation Project. This study is based on the assumption that college students are neither trained nor expert readers, but readers in the process of formation who suffer the same problems as precarious or superficial readers and, therefore, must diagnose and correct their own situation as the best example and training for their involvement in classroom contexts. Their heuristic and self-reflective qualities are assessed in light of the professional skills of teachers.
\end{abstract}

\section{Keywords}

University teaching; teacher training; teaching reading and writing; classroom research; Universidad de Extremadura, Spain (Source: Unesco Thesaurus). 


\title{
Alfabetização, gráficos e aprendizagem heurística
}

\author{
Resumo
}

Descrevem-se certos tipos de gráficos como ferramentas de pesquisa qualitativa utilizadas na formação de professores da Faculdade de Educação da Universidad de Extremadura (Espanha), a partir de um Projeto de Inovação Docente. Parte-se da hipótese de que os alunos universitários não são leitores formados nem especializados, mas sim leitores em construção, que carecem dos mesmos problemas dos leitores precários ou superficiais e que, portanto, devem diagnosticar e corrigir sua própria situação como melhor exemplo e treinamento diante da sua intervenção em contextos de sala de aula. Destacam-se suas qualidades heuristicas e de autorreflexão ante as competências profissionais do docente.

\section{Palavras-chave}

Pedagogia universitária; formação de professores; ensino da leitura e da escrita; pesquisa de sala de aula; Universidad de Extremadura; Espanha (Fonte: Tesauro da Unesco). 


\section{El marco teórico: de la cultura visual y la cartografía conceptual a la convergencia de medios y el enfoque constructivista}

Estamos en un contexto que bien podemos caracterizar con la noción de cultura compleja (Morin y Pakman, 1994) donde, en relación con el tema que abordaremos, pesan de forma extraordinaria algunos factores importantes. El primero, la eclosión moderna de la cultura mediática y visual, tras siglos de auge de la galaxia Gutenberg y su correlato, la cultura letrada (Chartier, 1992). El segundo, la revolución de la sociedad de la información, que en el caso de la educación ha propiciado tecnologías muy diversas y la necesidad de una alfabetización múltiple tecnológica, multimodal e intercultural (García Vera y Núñez, 2007).

Entre estos instrumentos y artefactos de la tecnología docente (Martos y García, 2014), cabe destacar lo que se viene llamando los mapas cognitivos y mentales que arrancan de los estudios de Ausubel y Novak (Novak, 2010), y, en general, de lo que se ha llamado cartografía conceptual o del conocimiento aplicada al aula (Okada, Shum y Sherborne, 2008). Un tercer elemento axial es el movimiento de convergencia; todos estos nuevos elementos culturales: convergencia de medios y participación serían, en efecto, las notas de esta nueva cultura (Jenkins, 2006), de forma que lo usual es que un contenido migre de un formato a otro o se genere de forma sinérgica entre varios lenguajes (transmedia). Incluso la teoría de la remediación (Bolter, Grusin y Grusin, 2000) nos explica qué pasa cuando un contenido es utilizado por otro medio. Pues bien, todos ellos son vectores que definen el campo de juego, de forma que la visualización, el aprendizaje, la multialfabetización y la cultura escrita interactúan.

En particular, vamos a tratar uno de los aspectos esenciales: el aprendizaje heurístico (Kim y Hannanfin, 2008), que constituye de hecho una aplicación de los entornos constructivistas de aprendizaje (Jonassen, 1999).
Para repensar la literatura y su enseñanza en el ámbito de la educación y, por tanto, extraer criterios de cara al uso, por ejemplo, de materiales didácticos, hay que subrayar el postulado constructivista de que lo importante no es buscar una "transmisión de la verdad", como si en la investigación se progresara hacia una única base de conocimientos (Novak, 1988). Más bien, el sujeto cognoscente es el organizador de su propia experiencia y constructor de su propia realidad, de modo que el sujeto que conoce construye un modelo propio del mundo. Según Novak (1988), el constructivismo humano es "un esfuerzo por integrar la psicología del aprendizaje humano y la epistemología de la construcción de conocimientos", y pone el énfasis en que "tanto en la psicología como en la epistemología debemos centrarnos en el proceso de fabricación de significados que supone la adquisición o modificación de conceptos y relaciones entre conceptos" (Novak, 1988, p. 220).

La creación de nuevo conocimiento es, pues, la forma esencial de aprendizaje significativo. Implica, al mismo tiempo, el reconocimiento de nuevas regularidades en los hechos u objetos, invención de nuevos o extensión de antiguos conceptos, reconocimiento de nuevas relaciones entre conceptos y, en los saltos más creativos, una gran reestructuración de las tramas conceptuales para que incluyan relaciones de orden superior. Estos procesos pueden ser vistos como parte del proceso de aprendizaje asimilador, que implica la adición de nuevos conceptos, la diferenciación progresiva de los existentes, el aprendizaje de orden superior (en ocasiones) y una nueva reconciliación integradora significativa entre las tramas conceptuales. Aquí es, por tanto, donde es posible instrumentalizar el aprendizaje heurístico (Blumenfeld, Mergendoller y Swarthout, 1987).

El modelo constructivista considera a la persona que aprende como una parte activa e interesada en el proceso de aprendizaje, y sus conocimientos previos juegan un papel decisivo cuando se "construyen" los significados en situaciones nuevas; los que aprenden van construyendo una concepción 
del mundo cada vez más cercana al modelo que acepta la comunidad científica. El alumno llega a la clase con unas ideas previas y el profesor debe tenerlas en cuenta. Pero además de tener su base en los estudios ya clásicos de Piaget o Ausubel, debemos recordar que el modelo constructivista se apoya también en la filosofía de Kuhn (1975) del cambio de paradigma entre los conocimientos previos y los adquiridos. Las principales características del modelo constructivista (Driver, 1988) afectarían a principios como los siguientes:

1. Lo que hay en el cerebro del que va a aprender tiene importancia.

2. Encontrar sentido supone establecer relaciones

3. Quien aprende construye activamente significados.

4. Los estudiantes son responsables de su propio aprendizaje.

5. Los objetivos de aprendizaje en el modelo constructivista aspiran a que el alumno alcance las ideas y los modos de pensar de los científicos.

Según Driver (1988), durante una secuencia de aprendizaje, los que aprenden deben recorrer un camino desde su estado de conocimiento presente a cierto estado de conocimiento futuro; la cuestión curricular es, ¿cuáles son las actividades de aprendizaje que hacen posible que esto ocurra efectivamente? Teniendo en cuenta que lo que se aprende en una situación determinada depende de la situación y de lo que aporta el que aprende, el diseño de aprendizaje debe considerar las investigaciones sobre el aprendizaje en el aula.

El profesor, en un modelo constructivista, desempeña un papel mucho más complejo que en un modelo transmisivo. Es un mediador entre el conocimiento de los científicos y el estado del conocimiento de los alumnos; por tanto, debe diagnosticar cuál es dicho estado, al mismo tiempo que debe tener un claro dominio de los conceptos científicos con los que va a trabajar, para diseñar las actividades apropiadas. No vamos a analizar los elementos o las fases de la secuencia de aprendizaje en un modelo constructivista, pero sí a subrayar el importante papel que corresponde este cambio de mentalidad en la praxis educativa a la hora de instrumentar, por ejemplo, los materiales didácticos.

\section{La praxis didáctica y el papel de los materiales gráficos en el marco de los parámetros del Espacio Europeo de Educación Superior}

En efecto, conforme a los postulados explicados, el docente debe estar "entrenado" en cómo activar la construcción del conocimiento en sus alumnos, desde el triángulo de actividad mental del alumno, contenidos de saberes culturales construidos socialmente y la propia función del maestro-mediador. El mediador ayuda a reconocer los rasgos significativos de su entorno, a filtrar y organizar los estímulos, y a lograr un sentido del universo.

La filosofía y los principios del llamado Plan Bolonia para la educación superior parecen inclinarse hacia un diseño de entorno formativo que aplique las pautas del aprendizaje constructivista. Coincidimos, a este respecto, con la opinión de B. Gros (2002) sobre que, más allá de la disparidad de propuestas, la mayor virtud de este enfoque es la de proporcionar un entorno complejo que puede ayudar a mejorar la educación y la formación necesaria para vivir en la sociedad actual. Dejando al margen estas cuestiones macroestructurales, coincidimos, a este respecto, con la opinión de B. Gros (2002) sobre que, más allá de la disparidad de propuestas y de su puesta en práctica, la mayor virtud del enfoque del Espacio Europeo de Educación Superior (EEES) es la de inducir un entorno complejo susceptible de ayudar a mejorar la educación y la formación necesaria para vivir en la sociedad actual.

En todo caso, esta opción debe traducirse en parámetros propios de los Emtornos de Aprendizaje Constructivista (ECA). En efecto, siguiendo la exposición 
de M. Esteban y M. Ros (2008), así como las explicaciones de C. Coll y J. Onrubia (2001), cabe subrayar que la diferencia esencial es que la información en sí no es ya el foco de interés, sino lo que "hacemos con ella". De ahí que el núcleo central del diseño sea el conjunto de propuestas, tales como la pregunta o tema, los ejemplos, el problema o el proyecto que los alumnos han de abordar, elaborar y resolver. O como subraya Esteban, mientras en este (enfoque objetivista) se parte de los conceptos y de la información en sí misma, en el modelo EAC se parte de los problemas, los ejemplos o de los proyectos o problemas y, mediante ellos, se llega a la información y a elaborar los conceptos adecuados.

En suma, todas las técnicas enunciadas (cognitive tools las llama Jonassen, o bien artefactos (Martos y García, 2014), se basan en los mismos supuestos de aprendizaje, que son el aprendizaje activo, constructivista y real. Los criterios para optar por una u otra herramienta van a depender de factores contextuales y otros como los estilos de aprendizaje, los recursos disponibles y otras variables, pero el caso es que se activen unos mecanismos de aprendizaje distintos a los convencionales.

Por ejemplo, las preguntas en el aula (Adame, 2000) servían tradicionalmente para subrayar algún elemento del proceso de enseñanza-aprendizaje y apenas se dejaba tiempo para que, más allá de la mera repetición de respuestas consabidas, el alumno pensara sobre lo cuestionado, formulara él a su vez otras preguntas, etc. En el caso de la literatura infantil, hay preguntas nucleares, como "ipor qué la literatura infantil es una literatura reciente?", lo cual lleva a todo un conjunto de indagaciones, esto es, a otras subpreguntas y matizaciones. Siguiendo con la aplicación del entorno constructivista de aprendizaje, con la propuesta de ejemplos, en el caso de la literatura infantil, podemos examinar toda clase de hechos o experiencias dignas de interés para la docencia de la misma, por ejemplo, el éxito de libros o películas como Harry Potter, La Historia Interminable, Peter Pan, entre otros, y la contextualización de estos hechos en el aula infantil, pues probablemen- te la "recepción" o lectura de estas obras va a depender mucho de la clase de realidad escolar y social en la que se ubique el futuro maestro.

Un área privilegiada de ejemplos es la que representan el estudio de los escritores en cuanto que obliga al alumno a situar estos textos dentro de una memoria cultural y literaria, por ejemplo, el concepto de niño travieso o rebelde y las distintas visiones de la infancia, la moral o la pedagogía, que perfectamente documenta la historia de la literatura infantil (García Padrino, 1992). La técnica de proyectos se piensa idónea para unidades educativas integradas a largo plazo, donde los alumnos deben centrarse en trabajos complejos que integren o conformen un proyecto con entidad suficiente como, en el caso de la literatura infantil, elaborar un canon de lecturas.

La técnica de problemas es en realidad un comodín que podemos aplicar a perspectivas y asuntos diversos. Así, el carácter controvertido de la existencia o no existencia de la literatura infantil, o la dificultad de su caracterización, o el deslinde entre obras infantiles y juveniles, todo ello se presenta como problemas que requieren todo un complejo armazón mental, que pasa por la clarificación de hechos, argumentos, hipótesis, etc.

Se ha dicho, y con razón, que formular bien un problema es "encarrilar" en gran medida una investigación, y lo mismo pasa con la docencia. A veces los problemas se formulan mal porque se simplifican, 0 presentan demasiadas incertidumbres en sus propios términos, o no se facilitan los mecanismos para que el alumno establezca juicios relevantes sobre el mismo, por ejemplo, el alumno carece de una buena documentación al respecto y se cae una y otra vez en estereotipos.

Ocurre, por ejemplo, cuando se debate sobre la forma y los contenidos del cuento de hadas, y no se han ilustrado conceptos o formas de lectura. También los periódicos, las revistas especializadas y las noticias son otra fuente de obtención de problemas. En todos ellos aparecen problemas de muy diversa índole, na- 
turaleza y materia que necesitan solución. Los problemas en la EAC necesitan incluir tres componentes integrados: a) el contexto del problema, b) la representación o la simulación del problema y c) el espacio de manipulación. Se da singular importancia a la presentación del problema, y no precisamente en formatos convencionales, es decir, al hilo expositivo; Jonassen (1999) habla de usar medios alternativos, como la narración, el multimedia o incluso la realidad virtual, lo cual nos recuerda al docudrama y formatos parecidos. Además, se insiste en que los problemas deben ser reales, esto es, conectados a hechos inmediatos o que tengan interés para los alumnos.

En cuanto al espacio de manipulación del problema, entendido en un sentido no solo físico, ha de definirse un ámbito donde se concreten los propósitos, las señales y las herramientas necesarias para que el alumno manipule el entorno, por ejemplo, el taller de lengua y literatura (López Valero, 2003) como espacio físico y mental donde los alumnos pueden dialogar, hacer puestas en común, cotejar o descartar elementos de un tema, un proyecto, un problema o cualquier otra técnica que aborden. Estas técnicas persiguen aumentar la flexibilidad cognitiva del alumno, pues a nadie se le oculta que las preconcepciones (Dennett, 1993) en literatura infantil son muy fuertes, y una de las más arraigadas es que se trata de una literatura "menor" o donde no se impone la calidad literaria como meta final. Por eso, para aumentar la flexibilidad cognitiva, es importante que los ejemplos relacionados ofrezcan una diversidad de puntos de vista y de perspectivas sobre el caso de estudio o proyecto que se esté resolviendo. En todo caso, el profesor debe abordar una planificación del proceso de enseñanza / aprendizaje interactivo y cooperativo, que no procede abordar aquí.

\section{Aprender lengua y literatura con gráficos según su tipología y modalidades de lectura}

No vamos a referirnos solamente a los organizadores gráficos, a pesar de que es el tipo de material más practicado (Novak y Gowin, 1984; Toro Se- govia, 2012), sino a toda la pluralidad de materiales gráficos, desde el clásico y tradicional cuadro sinóptico a la infografía más elaborada y el software por ordenador (Hannafin et al., 1997).

El aprendizaje heurístico, basado en la propia experiencia y el descubrimiento, necesita de todas estas herramientas, de elucidar sus criterios de uso y de un eclecticismo ponderado. La "carpintería del aula" (Martos, 1995) ha cambiado radicalmente al trabajar ya con pizarras digitales e Internet como nuevas interfases didácticas y, sobre todo, a la hora concebir el material didáctico, que ya no es nunca autosuficiente - a diferencia del libro de texto clásico-, lo cual hace que se pueda acudir a una pluralidad exultante de materiales. Hasta el punto de que cabe hablar de una hipertrofia de la imagen que lleva, por vía de la vanguardia tecno-industrial, a elevar la imagen a un simulacro o espectáculo sucedáneo de la realidad (Subirats, 1988). Este carácter "espectacular" se refuerza en las animaciones o en la infografía, la imagen es ante todo atrayente, y todo ello ha hecho cambiar el panorama de los medios a disposición del docente universitario (Tejada, 2002).

Lo de menos en este enfoque es el computador, convertido en una especie de rotring de lujo, o la aplicación informática en sí; lo pertinente es cómo "se gestionan" las ideas: la elaboración propia, el indagar conocimientos o el compartirlos con los "iguales", todo lo cual abre un campo amplio al aprendizaje activo y colaborativo, y a la idea de inteligencia colectiva que subyace a la propia creación de Internet. Ciertamente, los alumnos ya están habituados a una "dieta" de imágenes fuertes, trepidantes o efectistas que impregnan el cine, los videoclips o la televisión. En este contexto, el gráfico no solo sirve como simplificación de la información respecto a la imagen figurativa, sino que posibilita otro tipo de lectura mucho más reposada y reflexiva. La versatilidad, por ejemplo, con que leemos un gráfico, nos permite hacer una lectura de ojeo y convencional, esto es, de arriba abajo y de izquierda a derecha, pero también nos permite una lectura más propia 
de los signos icónicos, focalizando una determinada zona o conexión.

Es verdad que no existen solamente los mapas cognitivos, sino que cabe hablar de una gran variedad de grafismos. Por ejemplo, las analogías (García Rivera y Núñez, 1993), es decir, gráficos figurativos que actúan como metáforas visuales para explicar conceptos de difícil asimilación. Analogías, por ejemplo, para hacer llegar al educando el concepto de palabra (bloque de ladrillos = sintagma, ladrillo = morfema, etc.) figurativo. En la misma línea, hay gráficos como los modelos, maquetas, etc., tales como los trenes que el médico Ch. Bru (1971) ideó para reeducar a los disléxicos. Tampoco nos podemos extender en las pictografías que se han utilizado desde los orígenes de la humanidad para presentar relatos o acontecimientos en imágenes y para, finalmente, alumbrar la escritura. Lo cierto es que los pictogramas (Martos, 2008) sirven de base a métodos de lecto-escritura y juegos gramaticales ( $\mathrm{Pi}$ Navarro y Girbés, 1991). Desarrollo psicológico y educación II. Psicología de la educación

Los llamados gráficos esquemáticos se oponen a los figurativos en el sentido de que se sustentan en un bajo grado de iconicidad, esto es, que albergan grafismos abstractos, como formas geométricas, rayas, flechas, etc. Son buenos, pues, en cuanto a manejabilidad y poder de comprensión, y, en ese sentido, son buenos para fijar o anclar un contenido, y más duraderos que el "chispazo" de un gráfico figurativo, por atrayente que sea. A veces echamos en falta un poco de variedad en tantos diagramas con un mismo esquema de base: es lo que sucede, por ejemplo, con cmaptools y con otras formas de mapas conceptuales. Sin duda, fueron concebidos (Novak y Gowin, 1984) para la enseñanza de las ciencias experimentales, y por tanto su composición se inclina más a ahormar conceptos que a promover la creatividad individual. Es verdad que a mayor procesamiento de la información, mayor estructuración y profundización de esta (Del Río,1989), y los gráficos esquemáticos son muy estructurantes.
Pero no solo en cuanto a creatividad, también presentan otros puntos débiles: su escasa relevancia para la memoria, pues son todos muy repetitivos en cuanto a formato, y no siempre son heurísticos en el sentido de explorar otra clase de conexiones que no sean las del pensamiento lineal inductivo-deductivo. Se habla, por ejemplo, de pensamiento lateral (Bono, 1970) y de aprendizaje divergente como marco para la creación de nuevas ideas, que implica desde luego recorrer itinerarios alternativos a la hora de comprender / construir un concepto.

\section{De los gráficos informativos a los gráficos heuristicos}

En resumidas cuentas, todo gráfico tiene unas ventajas indudables a la hora de ser comparado con la simple exposición verbal, pues presenta visualizada una información, ya sean datos, conceptos, secuencias, etc., que se captan, por tanto, de forma global, "de un vistazo”, a diferencia del signo lingüístico que es necesariamente discontinuo, discreto. Además, se pueden leer de forma más versátil que un mensaje verbal, ya que sabemos que un gráfico admite multiplicidad de lecturas, desde aquella en plano general, a la interpretación de detalles, sin olvidar otras posibles (de izquierda a derecha, de arriba abajo, en diagonal, en rotación...). Pero a estas cualidades que posee cualquier gráfico informativo, hay que añadirle otras, que solo son plenamente aplicables a los gráficos heurísticos: que son una herramienta importante para estructurar, fijar y recuperar información, pero también para buscar información nueva, "probando" nuevas conexiones.

Así, todo el arsenal de información que hay en Wikipedia, por citar un caso emblemático, es susceptible de representación gráfica, que ya no se limita a los índices o cuadros sinópticos de la enseñanza tradicional. Una aplicación como Wikimindmap ha desarrollado, mediante la técnica de mapas mentales, una herramienta para navegar con facilidad y eficacia en el contenido Wiki. Lo importante es que presenta los contenidos en forma de gráficos Freemind (figura 1). 
Figura 1. Ejemplo de Wikimindmap

\section{Wlkimindmep}

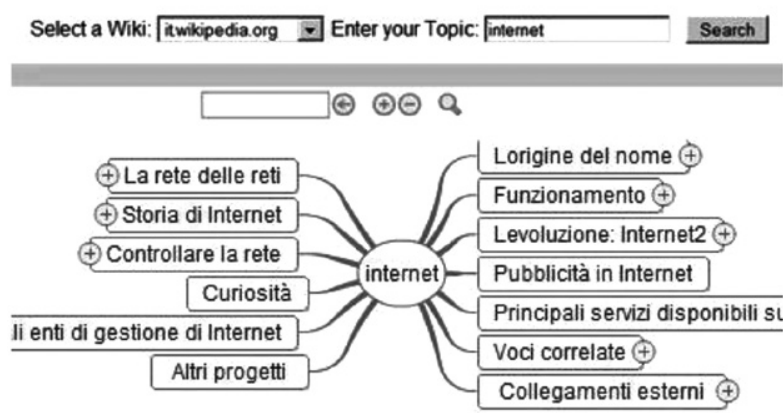

Vemos, pues, que tiene una forma reticular que visualiza los epígrafes del artículo correspondiente en Wikipedia. Lo interesante es que de un solo vistazo presenta la información estructurada y abierta a la vez. Si tenemos en cuenta que wikimindmap se ofrece en once idiomas, es fácil cotejar y contrastar cuáles son las estructuras de ese mismo artículo en diferentes lenguas. Así pues, el mapa es significativo tanto por las conexiones presentes como por las ausentes, y porque la relación hiperónimo-hipónimo es mucho más flexible, de forma que los agrupamientos y las jerarquizaciones también son mucho más heurísticas. Si consultamos la noción "tesoro", que puede ser lo mismo un tema arqueológico que de literatura o de otros ámbitos, constatamos la enorme riqueza y diversidad de datos, y podemos por consiguiente abordar el proyecto cognitivo de "aprender a desaprender", de superar las preconcepciones y de crear nuevas conexiones a partir de lo ya sabido.

En este caso, la indagación llevaría a cuestionar el estereotipo tesoro=cofre de monedas de oro, para indagar otros muchos itinerarios, como el que nos llevaría a la concepción griega del tesoro como agalma, una perspectiva absolutamente distinta al

1 Véase la diferencia entre la exploración en español, http:// www.wikimindmap.org/viewmap.php? wiki=es.wikipedia org\&topic=tesoro\&Submit=Search, y la exploración en in glés, http://www.wikimindmap.org/viewmap.php?wiki=en wikipedia.org\&topic=tesoro estereotipo de películas o del uso coloquial del concepto. En el itinerario en español de este concepto en wikimindmap, esto es posible porque hay numerosas conexiones con conceptos como esculturas, santuario, joyas, ornamentos, etc.

El fin último es que los alumnos no identifiquen la idea de tesoro simplemente con dinero, apropiación o codicia; se hace así viable a través de itinerarios alternativos que llevan además a una lectura hipertextual, a una práctica que equivale en fuentes de información a lo que es la teoría situacionista de la deriva (Debord, 1958). Esta búsqueda abierta de información lleva a menudo a hallazgos casuales (serendipia) (Roberts, 1989), que son motivados de forma heurística por gráficos como los citados, que presentan asociaciones a un concepto.

Pero a estas cualidades que posee cualquier gráfico informativo hay que añadirle otras, que solo son plenamente aplicables a los gráficos heurísticos: que son una herramienta importante para estructurar, fijar y recuperar información, esto es, una estrategia cognitiva de primera magnitud, si se sabe utilizar el tipo de gráfico adecuado para los contenidos, objetivos y niveles de desarrollo de los alumnos, es decir, si se sabe personalizar y "customizar" el tipo de gráficos en lugar de emplearlos de forma rutinaria, como complementación de la información verbal, al modo de los libros de texto clásicos.

En el estudio Utilización de los gráficos en el aula: métodos y ejemplos (García Rivera y Núñez, 1992) ya describimos en detalle cada modalidad. Lo que nos interesa aquí es reflexionar sobre los mismos a la luz de lo que creemos diferencia el uso de los gráficos como estrategia cognitiva: su carácter meramente informativo o bien su capacidad heurística y constructiva. Por ejemplo, las escenas son gráficos que representan una situación, y, como tales, sirven para describir y explicitar un marco comunicativo; informan de todo un conjunto de variables comunicativas (i. e. indicadores de situación), pero, en esa misma medida, tienen una capacidad 
de revelar lo invisible, lo implícito. Como en La carta robada de E. A. Poe, pueden poner de manifiesto lo que es más evidente, pero que, por una serie de causas, se halla solapado o sobrentendido. El uso de las escenas es normal en el aprendizaje de idiomas, naturaleza, etc., pero debiera volcarse más a suministrar estas pistas o indicios que puedan incidir en una conversación u otra situación comunicativa.

En cambio, en las analogías la función heurística es más evidente, en la medida en que son gráficos que implican una metáfora visual para explicar un concepto difícil de ser comprendido o interiorizado. Por ejemplo, en lengua o literatura hay conceptos, como palabra, estilo, figura retórica, etc., difíciles de ser aprehendidos. Analogías con capacidad heurística las hay múltiples (García y Núñez, 1993): así, varias piezas unidas formando un bloque = sintagma, tendido eléctrico = relaciones entre oraciones, lectura de un cuento $=$ recorrido de un tren, etc. $Y$ es sabido que el pensamiento analógico es una vía importante de la creatividad, en la medida en que se conectan campos sin relación aparente, de modo que seguir el recorrido de una analogía es algo más que hacer una alegoría: sirve para descubrir facetas inadvertidas y recabar en puntos importantes del problema.

Por el contrario, las maquetas y modelos tienen una función más informativa, al igual que los emblemas, logotipos, simbolos y otros gráficos figurativos que varían en el grado de iconicidad, pero no en su orientación, al presentar una información simplificada. En el caso de las caricaturas, se inclinan a deformar rasgos de la realidad, subrayando y estilizando ciertas cualidades o atributos. El humor gráfico está lleno de estas estilizaciones, y hay que estimularlas en los alumnos, pues se vincula a una amplia tradición satírica. En eso justamente se diferencian de los pictogramas - tan útiles en el aprendizaje de la lectoescritura - pues estos carecen del citado afán singularizador y, como en las señales de tráfico o logotipos de los hospitales, son formas muy geometrizadas.
En lo que respecta a las gráficas, ya dentro de los gráficos esquemáticos, la capacidad constructiva no está en el diseño de las mismas, si acaso en su forma peculiar de lectura o interpretación, ya que al poner en correlación varias magnitudes o masas de datos exigen una habilidad relacional ligada a ciertas capacidades cognitivas. En contraste, los diagramas tienen una virtualidad importante de organizar conceptos, aunque sea una organización cerrada y poco permeable a nuevas conexiones. En efecto, un diagrama "encarrila" unos conceptos según unas señalizaciones convenidas, esto es, según un marco esquemático donde adquieren un valor convencional las formas geométricas, los trazos, el color, etc.

Llegamos, pues, a la conclusión de que la función básica de los diagramas es la de estructurar la comprensión, aunque sea a menudo de una manera cristalizada, a diferencia de las redes de conceptos. Con todo, la articulación de los conceptos o informaciones en proposiciones más simples es una pieza básica o un apoyo importante al razonamiento, y de hecho algunos trabajos experimentales demuestran que el resumen $u$ otras destrezas similares se mejoran cuando los textos se acompañan de diagramas explicativos o secuencias ordenadas como las que contiene un diagrama de flujo.

Por otra parte, nada impide que un diagrama se combine con una analogía, beneficiándose mutuamente de sus ventajas. Por ejemplo, una silla, con su asiento, respaldo y patas, puede servir de marco de diagrama para un concepto "tripartito" (pensemos, por poner un caso, una presentación histórico-literaria del Lazarillo de Tormes, con sus fuentes o precedentes y sus repercusiones). A este respecto, también existen diagramas acrósticos, en forma de letras, que estructuran de manera muy eficaz diversos subconceptos (v. gr. diagrama de Gowin) (Novak, 1984).

Por su parte, los diagramas de estudio que tanto usan los estudiantes son, en realidad, bosquejos de redes de conceptos, y se han puesto de moda a medida que ha aumentado el papel de las técnicas 
de trabajo intelectual y su peso dentro del currículum. Un ejemplo es Spiderscribe, una aplicación on line para construir diagramas, que permite combinar texto, imagen, georreferenciar, etc. (figura 2).

Por otra parte, la indefinición de muchos diagramas tiene mucho que ver con el bajo nivel de resolución con que almacenamos algunas representaciones figurativas, bien sea por motivos culturales, preferencias personales, etc. Así, si preguntamos a un hombre que acaba de visitar una peluquería qué había allí y esta persona tiene escaso interés por la cosmética, sus representaciones serán puramente emblemáticas, apenas se habrá fijado en los detalles de tal o cual aparato. Así que el bosquejo, el bajo nivel de resolución es un mecanismo normal en la formación de imágenes, y ayuda justo cuando no queremos retener más información que la necesaria. ¿Por qué, pues, añadir perfiles o líneas precisas a una protoorganización de unos datos o informaciones, tomadas en forma de apuntes, notas para un trabajo, etc., cuando lo que importa es justamente este nivel inicial de preestructuración? Todo lo contrario es lo que ocurre con un organigrama, donde las dependencias están ya fijadas y consolidadas, y no es posible salirse un ápice de las relaciones establecidas, a no ser que sea para realizar una lectura creativa del mismo. Hasta ahora hemos venido hablando de gráficos para representar datos, o de aquellos otros de carácter figurativo que sugieren o vehiculizan conceptos, como las analogías. Sin embargo, la gran aportación de los gráficos a la adquisición de conceptos es los que llamamos genéricamente redes de conceptos.

En efecto, las redes de conceptos arrostran la tarea más difícil, la de enseñar conceptos y relaciones entre los mismos. No es casualidad que haya sido en el campo de la didáctica de las ciencias experimentales donde esta técnica se haya usado con más éxito, al amparo de las teorías de Ausubel, Novak y Gowin, como material instructivo y sobre todo

Figura 2. Gráfico en Spiderscribe del autor

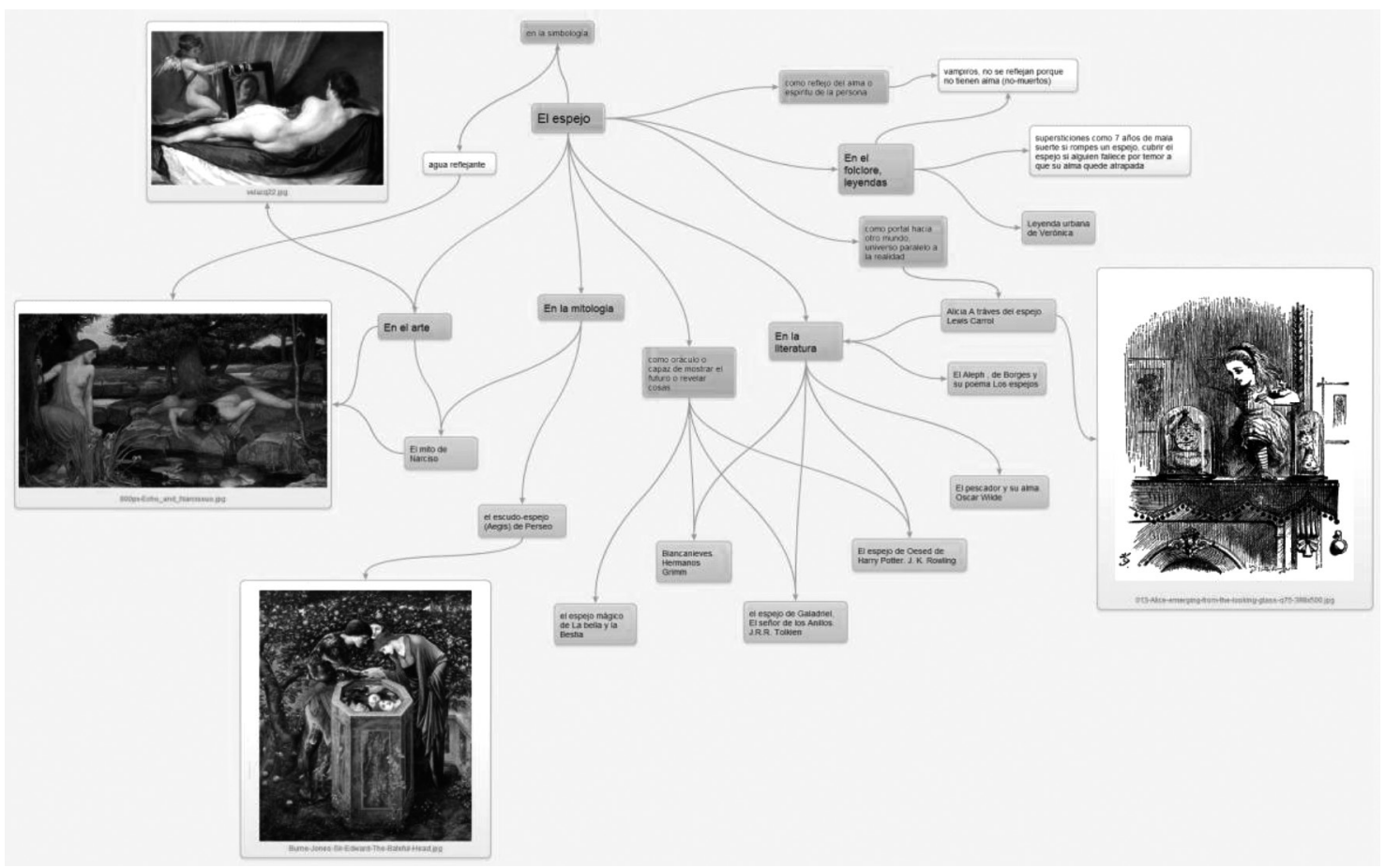


como estrategia cognitiva orientada a ayudar a que el alumno explore, indague y construya redes conceptuales, más que como un simple apoyo o refuerzo gráfico.

Por otra parte, estos procedimientos inciden positivamente en dos problemas que suelen recibir escaso tratamiento operativo en la escuela. Primero, ayudan a motivar la enseñanza en la medida en que está demostrado que la falta de la misma se relaciona con deficiencias en la comprensión. Segundo, sirven de forma diversificada a distintas clases de alumnos, es decir, destacan con ellos los alumnos que no solían sacar buenos porcentajes en las pruebas objetivas. Parece demostrada, pues, una correlación positiva entre la realización de mapas y una mejora en los resultados de los exámenes, lo cual se debe en última instancia a que constituyen una técnica adaptada a diferentes estilos cognitivos. Además, hay una cierta confusión terminológica, ya que algunos autores hablan indistintamente de mapas de conceptos y mapas semánticos. Por el contrario, cuando hablamos de aquellos, admitimos toda clase de categorías conceptuales, es decir, admitimos todas las ideas que tienen relación lógica (González y Jáuregui, 1992). Ahora bien, un mapa semántico no tiene que ser la traslación de relaciones lógicas sino que, por ejemplo en el caso del campo léxico de sol, se relacionaría con otras palabras de dudosa implicación lógica (v.gr. sol es un sustantivo masculino, rasgo lingüístico que le opone a otros astros femeninos). De Saussure (1916) ya hablaba de estos mapas asociativos léxicos como una forma del funcionamiento paradigmático de la lengua. Independientemente, las técnicas con un mapa de conceptos son distintas de las se aplican con un mapa semántico: en aquel prima lo que Ausubel llama los principios de diferenciación progresiva de conceptos y la reconciliación integradora; en el mapa semántico lo que aplicamos es una especie de lógica de clases, eso sí, desde una perspectiva lingüístico-comunicativa, que, como veíamos en el ejemplo del sol, hace unir cosas que solo tienen un vínculo lingüístico o psicológico.
Así que en un mapa semántico, propiamente hablando, no se deberían admitir más que aquellas categorías gramaticalmente idénticas, por ejemplo, terminar vs. empezar, pero no terminar vs. comienzo. De hecho, el método estructural en semántica se basa en la identificación de clases y de definir ahí las oposiciones pertinentes (v.gr. como / comía, por / para, hoy / mañana...). Los mapas semánticos son, por así decir, itinerarios de los usos del lenguaje, y no la traslación de proposiciones o dependencias lógicas. Así, el sol es un tópico de conversación que manejamos en diferentes situaciones de comunicación y y en cada una de ellas funciona de distinta manera; así, como tema coloquial general, sol se contrapone a frío (hace sol, aprieta el sol...), es decir, se asocia a la temperatura. Ciertamente, cada gráfico tiene su utilidad, pues aprender relaciones de sinonimia, antítesis, etc., es también aprender una forma de implicación, siempre que sepamos distinguir los niveles y no solaparlos.

A saber, el concepto es un constructo mental, y los significados, una relación entre los elementos del código, aunque, como decimos, es bueno considerar la interpenetración de ambos niveles, en la medida en que manejar bien los códigos ayuda a desarrollar el pensamiento formal. J. Novak y D. Gowin (1984) dan una visión clara del tema cuando afirman que los mapas conceptuales tienen por objeto representar relaciones significativas entre conceptos en forma de proposiciones. Así pues, el verdadero objeto de los grafismos de un mapa conceptual es sustituir la lógica proposicional, donde cada "caja" u "óvalo" representa un argumento y su unión, el enlace lógico, como veíamos en el mapa sobre el sol: el sistema solar está formado por el sol, los planetas y los cuerpos menores, que se iconificaban mediante una "caja central" de la que se ramificaban tres "subcajas". O sea, el mapa de conceptos es una visualización de proposiciones, y, en esa medida, un instrumento heurístico de primera magnitud , pues no olvidemos que el mapa conceptual cambia -a diferencia del diagrama, de estructura cristali- 
zada - a medida que le incrementamos datos o le introducimos nuevas conexiones.

En definitiva, el mapa conceptual es una forma de esquematización para representar un conjunto de significados que a su vez obedecen a una lógica proposicional. El quid de la razón de emplear esta técnica está en la idea de que los mapas conceptuales dirigen la atención, tanto del estudiante como del profesor, sobre el reducido número de ideas importantes en que debería centrarse cualquier tarea específica de aprendizaje: construir, subordinar, diferenciar, distinguir los elementos supraordenados de los subordinados, las relaciones verticales de las horizontales, los ejemplos de los conceptos.

Es muy certera la formulación de Novak (1989), en cuanto a que un mapa, un diagrama o un gráfico cualquiera empiezan a ser efectivos si son capaces de aislar y perfilar lo que queda envuelto por él, separándolo de todo lo demás, es decir, si actúan como verdaderos marcos cognitivos. Tampoco debe perderse de vista el carácter jerárquico que deben tener, es decir, no cualquier ruta está permitida (Novak, 1989), de manera que la forma de una jerarquía conceptual es en cierto modo aleatoria, cualquier concepto puede ocupar el escalón más alto en función del trenzado o la red que queramos describir.

Esto es, a nuestro juicio, una puerta abierta para fundamentar que el profesor coloque ahí los inclusores que estime más oportunos para sus alumnos, de modo que puede partir de conceptos subordinados en una red de tinte inductivo, o viceversa, si quiere ir de lo más general a lo más particular. Con todo, los ejemplos de Novak describen casi siempre jerarquias descendentes, donde los conceptos supraordenados van arriba y los subordinados abajo, en sucesivos niveles. Probablemente sea lo mejor si pensamos que se trata de mostrar relaciones de interdependencia, que son muy fáciles de marcar cuando nos referiremos a hechos de las ciencias experimentales, pero que no son tan evidentes en las ciencias humanas, donde las relaciones son más cruzadas y heterogéneas. Cierto que, tomando como ejemplo la membrana de goma, se pueden cambiar los conceptos de posición, manteniendo relaciones proposicionales significativas con otros elementos del mapa.

De esto se deduce que los mapas conceptuales pueden ser una buena herramienta para organizar los contenidos de una unidad didáctica, esto es, no solo un material instructivo, de apoyo para la clase, sino una pieza importante en la elaboración de un proyecto o taller, y ahí es donde demuestra su gran capacidad heurística. Y también se deduce que es el profesor quien debe acomodar el mapa o la jerarquía conceptual a sus propios objetivos didácticos. Por consiguiente, si la forma de la jerarquía depende del uso y objetivo que pretendamos, entonces es posible establecer con diferentes tools (desde cmaptools o mindmapping y otros programas) distintas arquitecturas y formas de itinerar los mapas, que siempre serán formas abiertas y relacionables.

Es lo que ha pasado con Pearltrees, que es una herramienta 2.o que funciona en gran medida como los marcadores sociales. Su producto visible es la generación de "árboles de perlas" sobre cualquier temática que cada usuario puede crear y compartir, y que además se pueden reproducir en las redes sociales, en la cuenta de Twiter o embeber en un blog (figura 3).

De este modo, se puede decir que la aplicación va más allá de marcar favoritos para convertirse en una herramienta heurística de gran alcance, pues es el usuario y todos los conectados a estas perlas los que desarrollan la arquitectura de los distintos campos, creando ramificaciones y subcampos que participan de los rasgos habituales de los distintos productos de la cartografía conceptual, como los mapas de conceptos. Así pues, se puede resumir en que es una herramienta versátil, intuitiva y colaborativa, y que permite varios escenarios de producción y comunicación de contenidos, basados en la hiperconectividad. 
Figura 3. Ejemplo de Pearltrees

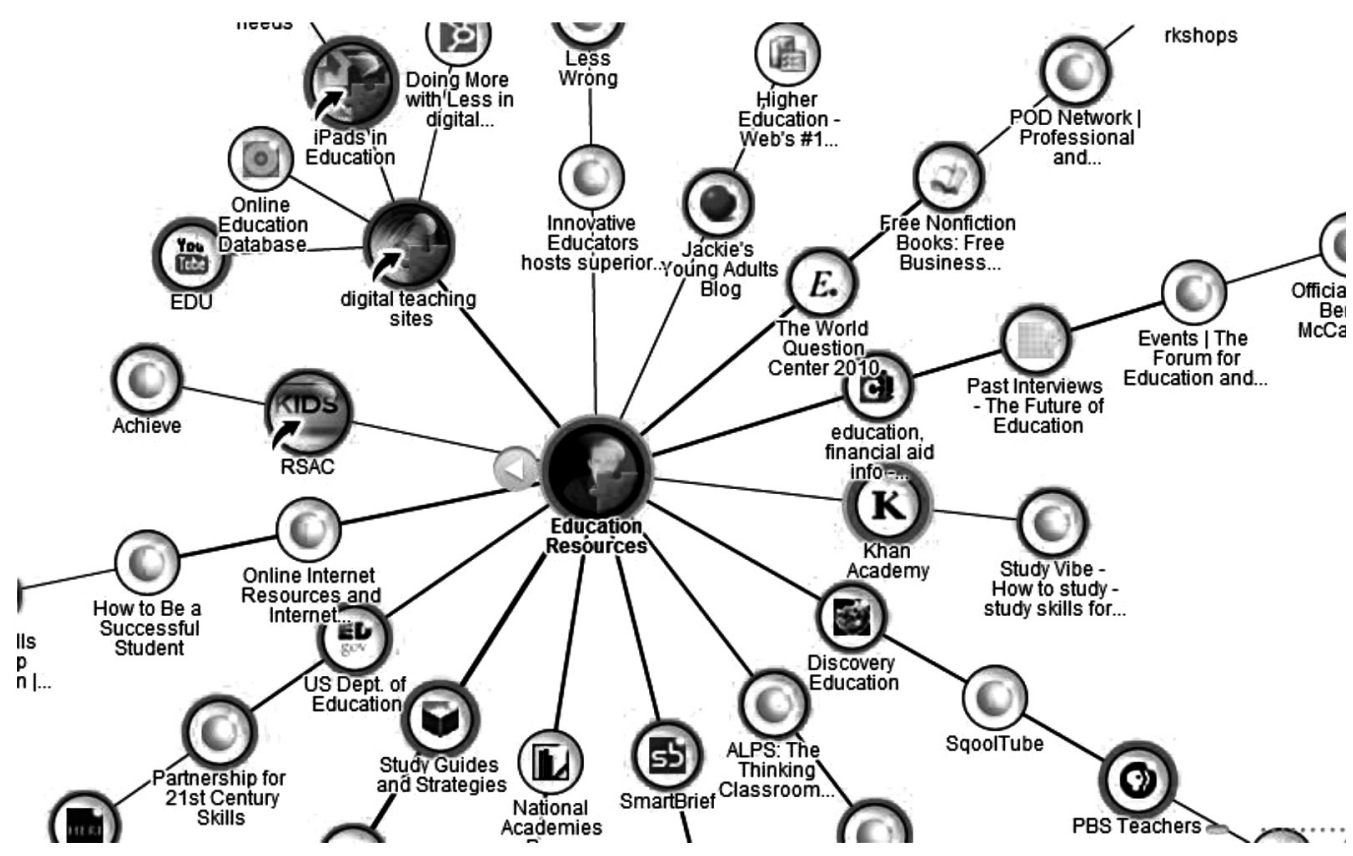

No vamos a extendernos en muchas otras clases de gráficos más propios del área de lengua y literatura, como por ejemplo las representaciones gráficas del análisis sintáctico, porque son de naturaleza muy específica y requerían un análisis de los paradigmas subyacentes, por ejemplo, los árboles de Chomsky. En cualquier caso, debemos insistir en aquellos que tienen un potencial heurístico mayor, como ocurre con los gráficos secuenciales: las líneas de tiempo, por citar un caso, sirven de entrenamiento cognitivo, en la medida en que exigen una lectura en forma de un trayecto dado. Funcionan también como tales los gráficos en diagonal, pues el ojo percibe como eje más significativo la línea inclinada. Es el caso de los gráficos en forma de cola de pescado, (diagrama de Iskisawa) (figura 4). También son buenos gráficos secuenciales los diagramas de flujo, en la medida en que ofrecen pasos pautados de un proceso.

Otro modo de gráfico secuencial son los gráficos de rotación o en circuito, es decir, aquellos que exigen una forma de lectura según las direcciones clásicas de un mecanismo de rotación o de un cir- cuito, como ocurre con los gráficos de relojes o en las simulaciones de una máquina "tragaperras". Similares a esta concepción de lectura guiada en una determinada dirección, son los itinerarios y las rutas, importantes en algunos campos específicos, como la representación espacial de un fenómeno (v.gr., viajes del Cid, rutas del Quijote, etc.).

Por otra parte, los gráficos que normalmente utilizamos son bidimensionales. Ahora bien, es posible diseñar gráficos tridimensionales con dos procedimientos básicos: que sean auténticamente tridimensionales (holografia) o bien que la tridimensionalidad sea fruto de un proceso de elaboración dentro de la imagen bidimensional (profundidad de campo, perspectiva...) lo cual nos lleva al terreno de los efectos, en especial al caso de los modelos y maquetas que han sido descritos como gráficos figurativos, pero que, por su propia naturaleza de ser simulaciones de una realidad, siempre tienden a una representación tridimensional. Así, un gráfico sobre un teatro será casi siempre la representación en perspectiva o transversal del escenario, bastidores, etc. 
Figura 4. Diagrama de Iskisawa

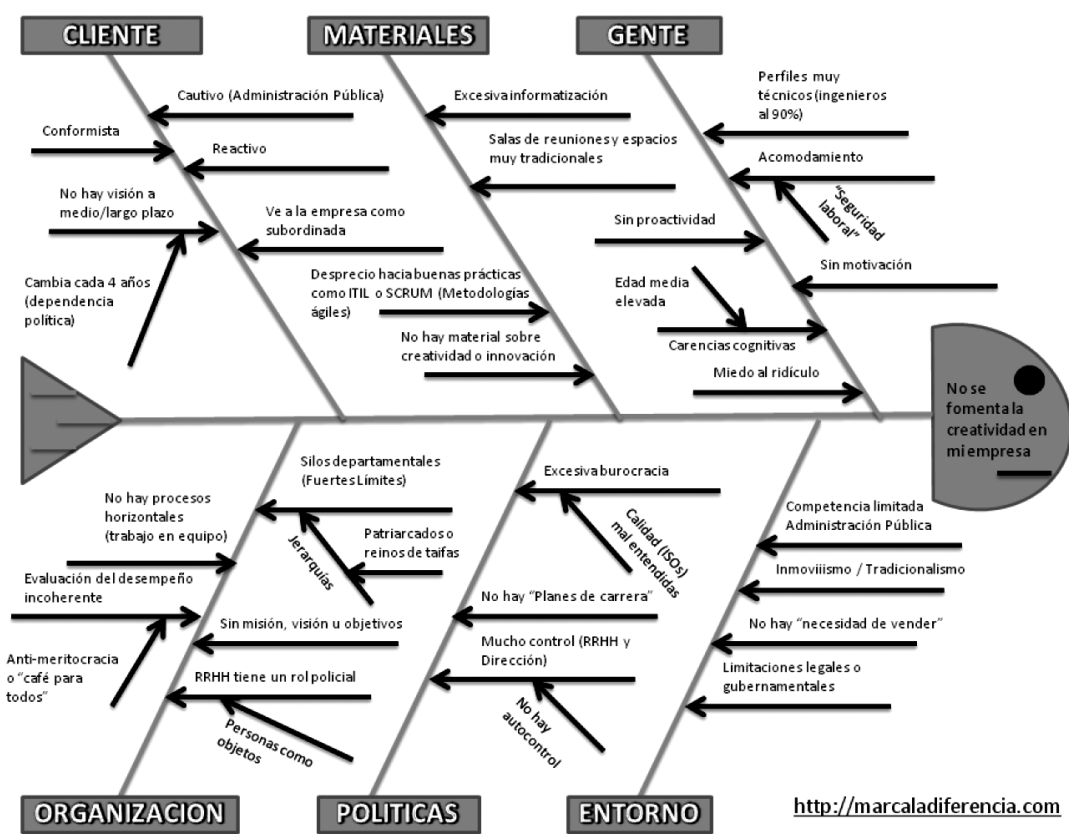

Igualmente importantes son los gráficos lúdicos: cualquier gráfico puede llegar a ser lúdico en la medida que permita un mayor número de interpretaciones o visiones del mismo. Por ejemplo, los gráficos incompletos y con veladuras. En todo caso, esta modalidad se emplea para hacer evaluaciones, haciendo que el alumno reconstruya lo "podado". Ahora bien, si estos gráficos impactan en el alumno no es porque sean pruebas de evaluación sino por el llamado efecto Zeigarnik (1938), que hace que los sujetos se preocupen más precisamente por aquellas tareas que consideran incompletas.

\section{A modo de recapitulación: los gráficos como artefactos educativos para la didáctica de la lengua y la literatura}

El contexto de una cultura logocéntrica, donde la principal industria de transmisión cultural estaba representada por la imprenta, y el "artefacto hegemónico" era el libro, ha cambiado sustancialmente. La evolución de las formas de la cultura escrita también ha ido dando lugar a los nuevos medios y lenguajes. La clase o lección magistral (normalmente entendida como discurso oral o leído) tenía como correlato el cuaderno o la toma de apuntes, y ese circuito se retroalimentaba: las notas o textos de una conferencia pasaban a formar parte de un libro, como vehículo básico del pensamiento científico, de la cultura letrada.

El papel de los esquemas gráficos era, en esta tradición, residual, como era en general el papel de la imagen. En cambio, el desarrollo del powerpoint y de todo el software que ha ayudado a representar la información de forma visual y dinámica, con introducción de numerosos códigos, ha cambiado sustancialmente la percepción. En este nuevo contexto, los gráficos se han popularizado en las últimas décadas como auxiliares didácticos, sobre todo a partir del boom de los mapas de conceptos y del creciente uso de diferentes softwares de gráficos (cmaptools, mindmanager, wikimindmap, etc.) como recurso didáctico. No vamos a tratar, pues, en este artículo 
de estos usos generales, sino que nos referiremos a ciertos tipos de gráficos que hemos utilizado para la formación del maestro en temas de lectura.

En el marco de los "Nuevos estudios de literacidad" (Barton, 2007) se han popularizado algunas herramientas gráficas alternativas, que son en realidad instrumentos cuasi-etnográficos que ayudan a describir las prácticas lectoras de una persona en concreto o de una comunidad alfabetizadora. Como ejemplos, adjuntamos los relojes de lectura, que registran los eventos o las prácticas letradas a lo largo de las horas de un día corriente en la vida de una persona, y los diagramas de ámbitos, que ubican dichas prácticas en alguna de las comunidades alfabetizadoras que frecuenta, bien sea la familia, la escuela, el trabajo...

El sentido de estas herramientas es entrenar al futuro profesor en la (auto)observación. Por un lado, estos gráficos visualizan, respectivamente, la distribución de prácticas lectoras / escribanas a lo largo del día, su distribución entre ámbitos / comunidades de alfabetización, y las propias experiencias lectoras y la forma en que se han articulado creando conexiones o asociaciones dentro de cada uno. Si esto se aplica a una observación más amplia que la de uno mismo, entonces estamos ante una herramienta de especial interés para la investigación cualitativa. Los etnógrafos de la lectura llaman a esta descripción sistematizada "inspección del paisaje", que no es más que una indagación guiada para describir un grupo de prácticas / eventos de lectura y escritura del grupo que pertenece al entorno que previamente acotemos, según este protocolo:

Tarea previa: determinar la zona de nuestra indagación. La zona acotada debe ser de ámbito local, e incluir algunas partes del mismo, seleccionadas a partir del conocimiento; por ejemplo, un colegio y su área de influencia (barrio, vecinos, centros culturales o de ocio próximos, etc.).

a) Identificar los enclaves de alfabetización, es decir, los puntos (instituciones, colegios, bibliote- cas centros culturales, edificios, etc.) donde se dan habitualmente estas prácticas alfabetizadoras. Se puede ayudar de la cartografía lectora de la localidad, si está hecha. ${ }^{2}$

b) Registrar los datos de los "eventos letrados" producidos en ese área (acontecimientos relacionados con las prácticas de lectura y escritura, en educación formal e informal, ocio, conferencias, tertulias y todo tipo de prácticas cotidianas y eventos donde la lectura y la escritura jueguen algún papel).

c) Identificar los participantes de esa comunidad local. Muestrear y aplicar estudios de casos.

d) Seleccionar un grupo de informantes y aplicarles a modo de cuestionario:

- Los itinerarios de lectura.

- Los relojes de lectura.

- El diagrama de ámbitos.

e) Seleccionar mediadores de lectura y otras personas emprendedoras y obtener "historias de vida" de su experiencia en torno a la lectura y la escritura.

Estos gráficos, pues, ayudarán a visualizar la situación real de un entorno de lectura y, en su caso, a identificar las iniciativas más innovadoras a nivel de la comunidad, y otros aspectos igualmente útiles, como la comparación de los patrones de lectura entre unos gráficos y otros. De hecho, los alumnos aprenden mucho cuando deben comentar los documentos de otros compañeros, sus redes de lectura, y, en su caso, las propias historias de vida, pues a menudo fomentamos que dichos gráficos sean glosados o verbalizados. Por ejemplo, un estereotipo que sale siempre para justificar las (escasas) lecturas de los

2 Véanse también los mapas y recursos disponibles en http:// www.google.es/literacy/, y las cartografías lectoras elaboradas a nivel de la Red de Universidades Lectoras, www.universidadeslectoras.org 
futuros maestros son las lecturas obligatorias en secundaria, lo cual no es óbice para que puedan valorar redes de otros compañeros donde aparecen lecturas muy diferentes, que se deban a iniciativas personales, influencia de buenos mediadores, etc. Con todo ello se visualizan las confluencias, los antagonismos o (falta de) colaboraciones entre la comunidad escolar, la comunidad familiar y la comunidad del entorno (barrios, amigos) como sustrato que explica la formación lectora de estos futuros profesores.

También suele quedar en entredicho la alfabetización académica, es decir, el grado en que los aprendizajes de lectura y escritura en el instituto y la universidad han contribuido a formar lectores. A la vista de todo lo observado, los alumnos debaten proyectos de intervención y actuaciones aplicables a la escuela que aúnen ocio, escuela, vida familiar, amigos, entretenimiento y vida personal, a fin de no incurrir en los mismos problemas y errores que ellos observan en su propia formación. Todos estos procesos de autoanálisis se hacen, no desde el aislamiento, sino com- partiendo el análisis de estos instrumentos en forma colaborativa: se pidió a los alumnos que comentaran los mapas y documentos de otros alumnos y los cotejaran a su vez con su propia experiencia.

\section{Los itinerarios de lectura como herramienta heuristica}

A la hora de identificar prácticas lectoras una herramienta muy adecuada son los itinerarios de lectura y escritura, pues son gráficos de red donde lo que importa son las conexiones que se establecen para ir de un punto a otro, las lecturas que se focalizan como nodos centrales y, de forma muy importante, lo que no se consigna en dicho gráfico, por diversas causas que luego es preciso analizar. Por ejemplo, casi todos ponen como ítem el Quijote u otros clásicos, pero el hecho de no aludir a otras muchas lecturas es sumamente indicador de que o bien no se conocen o bien no han jugado un papel importante en su experiencia lectora, ni siquiera obras clásicas como la Biblia.

Figura 5. Itinerario de lectura por alumno

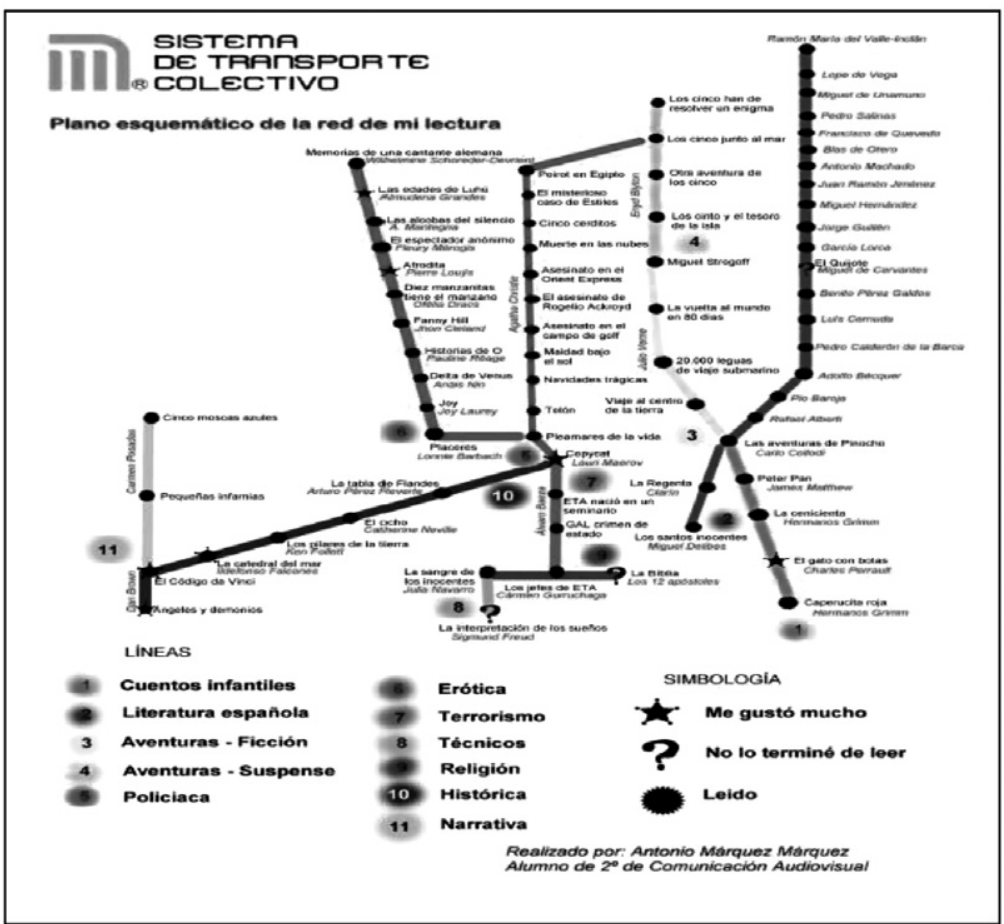


ISSN $0123-1294$ | Educ.Educ. Vol. 19. No. 1 | Enero-Abril de 2016 | pp. 121-144.

Universidad de La Sabana | Facultad de Educación

Puede ser conocer un autor, un texto, un género, un grupo de autores, actuales o clásicos, etc. Lo importante no es la distancia, la cercanía o lejanía que se establezca entre un punto y otro de la red, lo importante son las conexiones y los trayectos que se realizan. Para el fin que nos proponemos, el esquema que se sugiere es muy flexible, los nodos pueden ser autores, textos, incluso trozos o fragmentos de textos, géneros, y textos por supuesto no solo literarios y no solo impresos, se podían consignar comic, periódicos, etc. El caso es que el cuadro resultante nos diera lo que pretendíamos con la propuesta: "Mi perfil como lector/a", de modo que se pudiera explicar una especie de itinerario biobibliográfico que luego los alumnos aclaraban aún más en un breve texto redactado glosando el mapa (figura 5).

De este modo, conectamos también la lectura a creatividad, emprendimiento, iniciativa personal, ingenio... pues no buscamos lo que se repite (suelen ser las lecturas escolares del instituto) sino lo más personal o distintivo, y exploramos el porqué; a menudo ocurre que un abuelo o un amigo u otras influencia poco previsible sea lo que haya determinado que se haya leído ese texto.

La competencia lectora no se puede separar de la competencia transmedial. Los mejores lectores son capaces de saltar o de hacer zapping entre un código o lenguaje y otro, por ejemplo, son capaces de conectar los textos de Poe con la película, el cómic, Youtube, etc. Es lo que pretendimos al ponerlos como ejemplo "MetroPoe", un itinerario de lectura elaborado por el profesor J. Aguirre de la Universidad Complutense, que pretendía imitar el típico gráfico secuencial o croquis de redes de metro o autobús, donde en efecto se trataba de visualizar conexiones y "ramales" (en este caso sustituidos por géneros o agrupaciones ad hoc). En este otro gráfico (de reverso) se mostraban las claves de dichos "ramales", identificados en este caso por códigos de colores (figura 6).

Cierto que este itinerario de la lectura, aunque centrada en un solo autor, revelaba a un lector ex-
Figura 6. Itinerario Blog Monstruo Poe

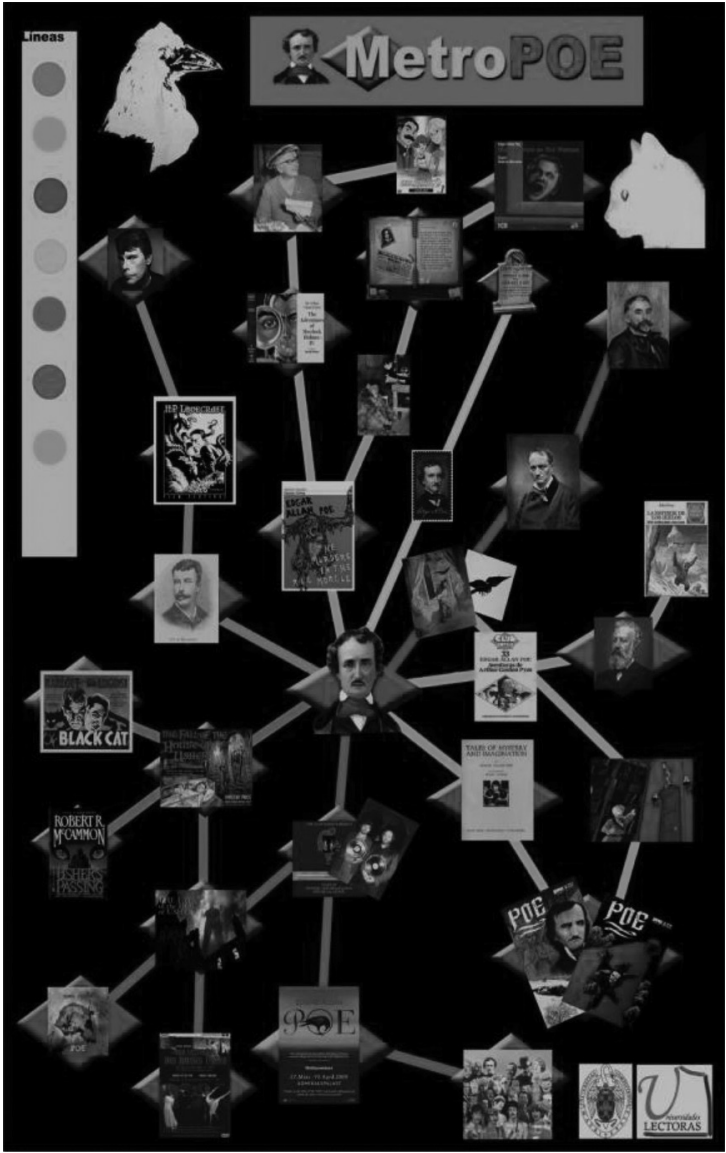

perto, capaz de establecer múltiples conexiones textuales, tanto literarias como multimediáticas, pero en esa medida era un modelo de lo que se les pedía, y que algunos alumnos imitaron para crear sus propias redes de lectura. En realidad, lo importante de estos itinerarios de lectura es que descubren el habitus (Bourdieu, 1999), la conformación mental y física con que se abordaron esas experiencias de lectura. Por ejemplo, el canon escolar propone siempre unos itinerarios jerárquicos, con lecturas axiales y lecturas marginales, y además en un recorrido pautado, bien cronológico, por géneros, etc.

Cuando se pide a los alumnos que tracen su propia red de lecturas, el canon escolar ocupa la parte mayor de esos itinerarios, con conexiones previsibles y poco abiertas a lo imprevisible, a lo creativo o em- 
prendedor. El caso del itinerario sobre Poe, tal vez por la personalidad del autor, es justamente lo contrario. Ciertamente, estos mapas de lectura se parecen mucho a los mapas mentales donde lo que se pone son las referencias que el estudiante construye.

Por su parte, la web de Itinerarios de Lectura ${ }^{3}$ pone en práctica estos mismos principios, con un mapa central sobre clásicos de la literatura universal, que se colocan como puntos yuxtapuestos sobre los que el internauta puede explorar. Por otro lado, sabemos que el elemento que esté en la cúspide de un mapa conceptual no es lo importante, lo que importa son las conexiones; con esto queremos decir que el Itinerario de Lectura es un mapa heurístico porque el alumno descubre las asociaciones e interacciones que se van produciendo entre ese referente y los conocimientos nuevos. El ciberespacio y la cibercultura ya tienen tanto peso que se habla con razón de ciberciudadanos. Las prácticas ligadas a la web 2.0, por ejemplo, son un modelo de ciudadanía y también ellas trazan flujos de lecturas y escrituras entre sus participantes, que seguramente se diferencian de los itinerarios limitados a un ámbito más local.

Los itinerarios de lectura y escritura son, pues, como esos viajes turísticos a que aludíamos al principio. Son como menús a la carta. Salimos al encuentro de los textos por múltiples motivos, no siempre precisamente de orden literario o estético, a veces el vínculo es afectivo (lecturas de nuestra infancia) o motivacional (lecturas de deportes o de géneros de ficción preferidos). Esto se debe traducir en que es posible acentuar el papel mediador del profesor a la hora de orientar en los posibles "itinerarios" a que se presta el hipertexto. El profesor, ante el desorden inherente a la Red, debe ser un experto en sugerir lectura de textos integrados, es decir, debe ser un experto en intertextualidad, literatura comparada, artes en general, pues su propósito final es ayudar

3 Véase http://www.itinerariosdelectura.com/ITER/webApp/ $\mathrm{src} / \mathrm{main} \cdot \mathrm{html}$ a buscar nexos significativos (un hilo conductor) entre todo un material heterogéneo y dispar.

En la educación literaria clásica se estudiaba el texto de forma aislada, y se descuidaba la integración de este con otros textos y discursos, y en sus propios escenarios, que no es más que buscar ese hilo conductor del que hablábamos. Se impone, pues, la necesidad de una pedagogía que ofrezca los textos no solo como realizaciones, sino como partes de una práctica social, los textos en su marco social y comunicativo, y en relación con otros textos. El caso del Quijote sería un buen prototipo de todo ello, el estudio del texto aislado de su contexto o solo en su singularidad literaria, impide su consideración multifocal, como lo que es, no solo un signo literario, sino un documento paradigmático de su época y, en particular, de las prácticas de lectura y escritura, es decir, una especie de enciclopedia de los usos y textos de su tiempo; de este modo, ayudamos a percibir todas las dimensiones, lo intangible (la cultura literaria o el peso de las ideologías), pero también lo tangible (la materialidad del libro, la tecnología disponible en su época, y la forma de circulación o preservación de los mensajes, es decir, el mundo de la imprenta, la edición o las bibliotecas).

De este modo, llegamos a una visión renovada de la alfabetización, en congruencia con lo que defiende el documento de la Unesco sobre la Década de la Alfabetización de Naciones Unidas, que implica, como vemos, enraizar la práctica educativa en el contexto social, de ahí que se propugne diversificar enfoques, estrategias, medios y métodos, pues la alfabetización es altamente sensibles al contexto y la cultura, y está claro que no existe una única ruta o método "milagroso" que sirva para todos. En cambio, sí parecen fundamentales algunas estrategias básicas, como la corresponsabilidad de todos, incidiendo en factores a menudo poco valorados, como el papel de la familia en tanto agente alfabetizador. Además, la generación de estos itinerarios de lectura respeta los principios del aprendizaje constructivista: como asevera Ausubel (Madruga, 1990), el 
nivel más elevado de una red conceptual no es lo importante, porque se acomoda a los fines de la indagación propuesta, lo importante es el flujo de información que vamos conceptualizando. Para ello es importante subrayar la importancia de la lectura y la escritura como prácticas sociales y socializadoras (lo cual compensa la tendencia al "autismo" del internauta), a fin de potenciar una compresión más amplia del contexto social de la lectura, aunando los tres elementos clave: el texto, la actividad de leer y el lector.

Hay que interrelacionar los elementos verbales y no verbales para adaptarse a las formas multisensoriales de lectura en la actualidad (multi-literacidad) y, de paso, valorar la imaginación, la innovación y la creatividad. Es lo que la profesora Tonfoni ha llamado lectura holográfica. Como argumenta la profesora I. Leibrandt (2003), estas actividades habría que enmarcarlas en este proceso de acercamiento entre las humanidades y la tecnología, y desde luego la red y los multimedia pueden ser utilizados para el aprendizaje constructivista de la literatura.

Por lo demás, la aplicación de la informática procura fomentar un trabajo cooperativo ya que las diferentes destrezas pueden ser de mutuo beneficio y los distintos procedimientos animan a compartir los métodos y resolver problemas. Buscar soluciones a problemas y manejar grandes cantidades de información son, por tanto, destrezas que destacan hoy en día, a parte de la propia especialidad, en el perfil profesional. Indudablemente, los estudiantes necesitan adquirir "destrezas técnicas" (computer proficiency), sin embargo, no hay que olvidarse de la importancia del desarrollo de "destrezas analíticas" que los volverán especialmente atractivos en el mercado laboral. Además, la generación de estos itinerarios de lectura respeta los principios del aprendizaje constructivista: como acabamos de subrayar, el nivel más elevado de una red conceptual no es lo importante, porque se acomoda a los fines de la indagación propuesta, lo importante es el flujo de información que vamos articulando.
Los textos y la actividad misma de leer deben abrirse a los nuevos lenguajes y alfabetismos, situándose en contextos significativos, y no solo instruccionales, y el lector debe ser el foco de todo, en la medida en que él es quien construye el conocimiento con la ayuda de todos los recursos puestos a su disposición y bajo la guía del mediador (profesor, bibliotecarios, etc.). A este respecto, insistimos en que géneros propios de la literatura fantástica o juvenil, como las sagas, suponen una buena introducción a los nuevos géneros, y, en particular, como ejemplo de texto continuo que enlaza con otros textos o discursos.

Por su parte, las prácticas comunicativas que estamos describiendo como propias de la cultura escrita o "letrada", en el sentido de Chartier (1992), no son un simple bagaje cultural que se tiene en mayor o menor grado, sino que mediatizan no solamente el aprendizaje sino la propia identidad social y personal y configuran contextos donde estas pueden desarrollarse e implementarse. El diálogo con los textos -al igual que el diálogo entre D. Quijote y Sancho- es una práctica comunicativa deliberativa y colaborativa que fortalece los lazos sociales y sitúa al individuo en relación con los demás y, por ejemplo, promueve o reduce los espacios para "construir" diálogos y es un indicador muy significativo.

Bajtin, Forcat y Conroy (1974) abogan por la cultura de la plaza pública, que posibilitaba prácticas como la lectura en voz alta, el intercambio de notas o "billetes", etc., todo lo cual es hoy sustituido por nuevos ámbitos privados (la casa, el centro comercial, la oficina...) y por eso mismo poco dados a lo que más demanda la convivencia ciudadana: tolerancia, diálogo intercultural, inclusión de las minorías, y de ahí que el análisis de estas prácticas sea vital para un nuevo concepto de competencia cultural y social.

Las cartografias de lectura y escritura (Rincón, 1996; Campos y Martos, 2014) evidencian la necesidad de diseños horizontales de colaboración entre instituciones que tengan las nuevas prácticas culturales y al ciudadano como foco de su actuación, 
y que tengan en cuentan no solo los aspectos más materiales, por ejemplo, los recursos instruccionales o las instituciones que trabajan de algún modo en alfabetización, sino los aspectos más intangibles, como los factores ya citados, los nuevos alfabetismos y su percepción en el joven, la forma de abordar la intermedialidad, el influjo de la socialización horizontal, etc. Todo ello con la perspectiva clara de la construcción colectiva del conocimiento basada en el intercambio (Borrás, 2011).

Además, la lectura y la escritura - junto con la oralidad- no son prácticas sociales sin más; todas ellas vehiculan un patrimonio cultural intangible que va más allá de ser un "tesoro de palabras". Sus puntales básicos son la memoria y la tradición. Gracias a esto los niños tienen acceso a una herencia cultural amplísima, tanto local como nacional o internacional, dada la universalidad de las narraciones. Es lo que se llama el "Imaginario", que no debe ser sustituido simplemente con las adaptaciones modernas (factoría Disney), y, por tanto, la narración sirve también para estimular el pensamiento creativo y crítico, abriendo y ensanchando la mente. Así pues, enseñar utilizando la imaginación y la narratividad es una aproximación alternativa a la forma de enseñar y al currículo de la escuela obligatoria, tal como defiende K. Egan (1999).

\section{Referencias}

Adame Viera, A. F. A. (2000). Las Preguntas en el aula. Campo abierto: Revista de educación, (17), 171-200.

Bajtin, M. M., Forcat, J. y Conroy, C. (1974). La cultura popular en la Edad Media y Renacimiento. Barcelona: Barral.

Barton, D. (2007). Literacy: An introduction to the ecology of written language. Oxford: Wiley-Blackwell.

Blumenfeld, P. C., Mergendoller, J. R. y Swarthout, D. W. (1987). Task as a heuristic for understanding student learning and motivation. Journal of curriculum studies, 19 (2), 135-148.

Bolter, J. David, Grusin, R. y Grusin, R. A. (2000). Remediation: Understanding new media. Massachusetts: MIT Press.

Bono, E. D. (1970). Lateral Thinking. A Textbook of Creativity. London: Ward Lock Educational.

Borrás Castanyer, L. (ed.) (2011). Textualidades electrónicas: nuevos escenarios para la literatura. Barcelona: Editorial UOC.

Bourdieu, P. (1999). Meditaciones pascalianas. Barcelona: Anagrama.

Bru, C. (1971). How to insure general long range studies of dyslexic-dysorthographics at a level commensurate with their mentality. Revue Belge de Psychologie et de Pédagogie.

Campos Fernández, M. y Martos Nuñez, E. (2014). Cartografias lectoras y otros estudios de lectura: Lecturas en las universidades públicas andaluzas. Madrid: Marcial Pons.

Chartier, R. (1992). El mundo como representación: estudios sobre historia cultural. Barcelona: Gedisa. 
ISSN 0123-1294 | Educ.Educ. Vol. 19. No. 1 | Enero-Abril de 2016 | pp. 121-144.

Universidad de La Sabana | Facultad de Educación

Coll, C. y Onrubia, J. (2001). Estrategias discursivas y recursos semióticos en la construcción de sistemas de significados compartidos entre profesor y alumnos. Investigación en la Escuela, (45), 21-31.

De Saussure, F. D. (1916). Curso de lingüistica general. Akal universitaria: Edicion de 2000.

Debord, G. (1958). Teoría de la deriva. Internacional situacionista, 1.

Del Río, P. (1989). El currículum invisible: los medios de comunicación y la prensa en la escuela. Comunicación, lenguaje y educación, 1 (3-4), 153-165.

Dennett, D. C. (1993). Consciousness explained. London: Penguin UK.

Driver, R. (1988) Un enfoque constructivista para el desarrollo del currículum. Revista Enseñanza de las Ciencias (6), 109-120.

Egan, K. (1999). Fantasía e imaginación, su poder en la enseñanza primaria: una alternativa a la enseñanza y el aprendizaje en la educación infantily primaria. Madrid: Ediciones Morata.

Esteban Albert, M. y Ros, M. Z. (2008). Estrategias de aprendizaje y eLearning. Un apunte para la fundamentación del diseño educativo en los entornos virtuales de aprendizaje. Consideraciones para la reflexión y el debate. Introducción al estudio de las estrategias y estilos de aprendizaje. RED. Revista de Educación a Distancia, 8 (19).

García Padrino, J. (1992). Libros y literatura para niños en la España contemporánea. Madrid: Fundación Germán Sánchez Ruipérez.

García Rivera, G.y Núñez, E. M. (1993). Atlas de lengua y literatura española. Madrid: Akal.

García Rivera, G.y Núñez, E. M. (1992). Utilización de los gráficos en el aula: métodos y ejemplos. Badajoz: Alborán.

González, F.y Jáuregui, R. (1992). Elaboración de material curricular e instruccional acerca del tema La Tierra en el Universo utilizando mapas conceptuales y diagramas V. Congreso Las Didácticas Especificas en la Formación del Profesorado, Santiago de Compostela.

González, T., Bermejo, M. L. y Mellado, V. (2004). Los mapas cognitivos elaborados a partir de entrevistas, un procedimiento de análisis para comparar las concepciones del profesorado sobre la enseñanza de las ciencias. Concept Maps: Theory, methodology, Technology, 1, 431-438.

Gros Salvat, B. (2002). Constructivismo y diseños de entornos virtuales de aprendizaje. Revista de Educación, $328,225-247$.

Hannafin, M. J., Hannafin, K. M., Land, S. M. y Oliver, K. (1997). Grounded practice and the design of constructivist learning environments. Educational Technology Research and Development, 45 (3), 101-117.

Jenkins, H. (2006). Convergence culture: Where old and new media collide. NYU Press. 
Jonassen, D. H. (1999). Designing constructivist learning environments. Instructional design theories and models: A new paradigm of instructional theory. En Reigeluth, Ch. (2000), Diseño de la instrucción. Teoría y modelos. Madrid: Aula XXI Santillana.

Kim, H. y Hannafin, M. J. (2008). Situated case-based knowledge: An emerging framework for prospective teacher learning. Teaching and Teacher Education, 24 (7), 1837-1845.

Leibrandt, I. (2003). Hipercultura e hiperficción: una cuestión terminológica. Espéculo, 25.

López Valero, A. (2003). Creación literaria y talleres. En CEPLI, La formación de mediadores para la promoción de la lectura: contenidos de referencia del Máster de Promoción de la Lectura y Literatura Infantil. Cuenca: UCLM.

Madruga, J. G. (1990). Aprendizaje por descubrimiento frente a aprendizaje por recepción: la teoría del aprendizaje verbal significativo. En Coll, C. Desarrollo psicológico y educación II. Psicología de la educación. Madrid: Alianza Editorial.

Martos García, A. (2008). Poemas y cuentos con pictogramas como recurso para la lectura, escritura y otras habilidades comunicativas. Glosas didácticas: revista electrónica internacional de didáctica de las lengua y sus culturas, 17, 49-63.

Martos Núñez, E. (1995). La estimulación lingüística a través de la imagen: materiales y recursos transferibles entre lengua materna y lenguas extranjeras. Didáctica. Lengua y Literatura, 7,417.

Martos, E. y García, A. E. M. (2014). Artefactos culturales y alfabetización en la era digital: discusiones conceptuales y praxis educativa. Teoría de la Educación. Revista Interuniversitaria, 26 (1), 119-135.

Morin, E. y Pakman, M. (1994). Introducción al pensamiento complejo. Barcelona: Gedisa.

Novak, J. D. (1989). Helping students learn how to learn: A view from a teacher-researcher. Third Congress of Research and teaching in Science and Mathematics, Santiago de Compostela, Spain, September.

Novak, J.Y. G. y Gowin, S. D. B. (1984). Learning how to learn. New York: Cambridge University.

Novak, J. D. (1988). Constructivismo humano: un consenso emergente. Enseñanza de las Ciencias, 6 (3), Fantasía e imaginación, su poder en la enseñanza primaria: una alternativa a la enseñanza y el aprendizaje en la educación infantily primaria. Madrid: Ediciones Morata.213-223.

Okada, A., Shum, S. J. B.y Sherborne, T. (2008). Knowledge Cartography: software tools and mapping techniques. En Novak, J. D. (2010). Learning, creating, and using knowledge: Concept maps as facilitative tools in schools and corporations. London: Routledge.

Pi Navarro, V. E. P. y Girbés, M. D. P. (1991). Recursos didácticos en el área de lenguaje (juegos gramaticales, pictogramas). Alicante: Marfil.

Rincón, C. (1996). Mapasy pliegues: ensayos de cartografía culturaly de lectura del Neobarroco. Bogotá: Colcultura. 
ISSN 0123-1294 | Educ.Educ. Vol. 19. No. 1 | Enero-Abril de 2016 | pp. 121-144.

Universidad de La Sabana | Facultad de Educación

Roberts, R. M. (1989). Serendipity: Accidental discoveries in science. En Royston, M. R., Serendipity: Accidental Discoveries in Science. Weinkeim: Wiley-VCH.

Ruiz, C., Porlán, R., Da Silva, C. y Mellado, V. (2005). Construcción de mapas cognitivos a partir del cuestionario INPECIP. Aplicación al estudio de la evolución de las concepciones de una profesora de secundaria entre 1993 y 2002. Revista Electrónica de Enseñanza de las Ciencias, 4 (1).

Subirats, E. (1988). La cultura como espectáculo. Madrid: Fondo de Cultura Económica.

Tejada Fernández, J. (2002). El docente universitario ante los nuevos escenarios: implicaciones para la innovación docente. Acción Pedagógica, 11 (2), 30-42.

Toro Segovia, G. J. (2012). La elaboración de organizadores gráficos y su influencia en el proceso enseñanza-aprendizaje del área de lengua y literatura en los estudiantes de séptimo año de educación básica de la escuela "Juan Salinas" de la ciudad de sangolquí (Doctoral dissertation). Universidad Técnica de Ambato, Ambato.

Valero, A. L. (2003). Creación literaria y talleres. En La formación de mediadores para la promoción de la lectura: contenidos de referencia del Máster de Promoción de la Lectura y Literatura Infantil (pp. 123-128). Cuenca: Centro de Estudios de Promoción de la Lectura y Literatura Infantil (CEPLI).

Zeigarnik, B. (1938). On finished and unfinished tasks. A source book of Gestalt psychology, 300-314. 